TITLE:

\title{
Rheological properties of concentrated solutions of galactomannans in an ionic liquid
}

$\operatorname{AUTHOR}(\mathrm{S})$ :

Horinaka, Jun-ichi; Yasuda, Ryosuke; Takigawa, Toshikazu

\section{CITATION:}

Horinaka, Jun-ichi ... [et al]. Rheological properties of concentrated solutions of galactomannans in an ionic liquid. Carbohydrate Polymers 2012, 89(4): 1018-1021

ISSUE DATE:

2012-08

URL:

http://hdl.handle.net/2433/157343

\section{RIGHT:}

(C) 2012 Elsevier Ltd.; This is not the published version. Please cite only the published version.; この論文は出版社版でありません。引用の際に は出版社版をご確認ご利用ください。 
$9 *$ Corresponding author.

10 E-mail: horinaka.junichi.5c@kyoto-u.ac.jp

11 Tel: +81-75-383-2455

12 Fax: +81-75-383-2458

14 Key Words: galactomannan; molecular weight between entanglements; guar gum; tara gum; 
20 Abstract

The rheological behavior of galactomannans in concentrated solutions was examined by

using dynamic viscoelasticity measurements. Concentrated solutions of three galactomannans,

guar gum, tara gum, and locust bean gum were prepared with an ionic liquid

24 1-butyl-3-methylimidazolium chloride as the solvent. Each galactomannan solution showed

angular frequency dependence curves of the storage modulus and the loss modulus which were

characteristic of a solution of entangled polymer chains. The molecular weight between

entanglements $\left(M_{\mathrm{e}}\right)$ was obtained from the plateau modulus and the concentration dependence

of $M_{\mathrm{e}}$ showed $M_{\mathrm{e}}$ in the molten state $\left(M_{\mathrm{e}, \text { melt }}\right)$ to be $4.6 \times 10^{3}, 3.2 \times 10^{3}$, and $2.7 \times 10^{3}$ for guar gum,

tara gum, and locust bean gum, respectively. It was found that the material constant $M_{\mathrm{e}, \mathrm{melt}}$

depends on the mannose/galactose ratio of the galactomannans. The number of monosaccharide

units between entanglements in the molten state for the galactomannans varied within the range

all the galactomannans take a random-coil conformation in ionic liquid solutions. 


\section{Introduction}

Galactomannans consist of a main chain of $(1,4)-\beta$-D-mannose as units and a side group of (1, 6)- $\alpha$-linked D-galactose. Among them guar gum (g-gum), tara gum (t-gum) and locust bean gum (lb-gum) are specifically well-known. They differ in the mannose/galactose (m/g) ratio: $\sim 2$ for g-gum, $\sim 3$ for t-gum, and $~ 4$ for lb-gum (Sittikijyothin, Torres, \& Goncalves, 2005; Wientjes, Duit, Jongschaap, \& Mellema, 2000; Wu, Cui, Eskin, \& Goff, 2009; Wu, Li, Cui, Eskin, \& Goff, 2012). The three galactomannans have been widely used in the food industry as ingredients to enhance viscosities in processing (Cerqueira, Bourbon, Pinheiro, Martins, Souza, Teixeira, \& Vicente, 2011), but the degree of enhancement depends on the species, or more precisely the $\mathrm{m} / \mathrm{g}$ ratio. Similarly, how the $\mathrm{m} / \mathrm{g}$ ratio is important to consider the viscoelastic properties of the solutions has been reported by many research groups (Sittikijyothin, Torres, \& Goncalves, 2005; Wu, Cui, Eskin, \& Goff, 2009; Wu, Li, Cui, Eskin, \& Goff, 2012). The m/g ratio is really one of important factors determining the solution properties of the galactomannans, but the origin on the molecular basis is still controversial (Morris, Cutler, Ross-Murphy, \& Rees, 1981; Richardson, \& Ross-Murphy, 1987; Robinson, Ross-Murphy, \& Morris, 1982; Wu, Cui, Eskin, \& Goff, 2009). The galactose units are not randomly distributed along the main chain made of mannose for galactomannans, which generates a blockiness: galactose-poor blocks (g-poor blocks, i.e., mannose-rich blocks) and galactose-rich (g-rich) blocks on a chain. Of course, the 
54 blockiness is not clear, but the mannose blocks easily form molecular association through

hydrogen bonds, while such attractive interaction is small for the g-rich blocks (Sanderson,

1990; Urlacher, \& Dalbe, 1994). This intermolecular association, enhanced with increasing the

$\mathrm{m} / \mathrm{g}$ ratio, may explain the difference in solution properties of the galactomannans.

The viscoelastic properties of the concentrated solutions of galactomannans are controlled

firstly by the number density of entanglements on a polymer chain, as is the case of other homogeneous polymer liquids (Ferry, 1980; Doi, \& Edwards, 1986), and the number density is a material constant reflecting the molecular parameters of the polymer chains such as the stiffness of the polymer chain. The molecular weight between entanglements $\left(M_{\mathrm{e}}\right)$ is often used to describe the spacing between entanglements and $M_{\mathrm{e}}$ in the molten state $\left(M_{\mathrm{e}, \text { melt }}\right)$ becomes a material constant. It is interesting to know if the chain stiffness and accordingly the spacing between entanglements change with the $\mathrm{m} / \mathrm{g}$ ratio (McCleary, Amado, Waibel, \& Neukom, 1981). However, we have no information of the values of $M_{\mathrm{e}, \text { melt }}$ for the galactomannans at present. This is partly due to the difficulty in preparing concentrated solutions, solutions of overlapping polymers, of the galactomannans with conventional solvents. The aim of this study is to estimate $M_{\mathrm{e}, \text { melt }}$ for the galactomannans. It should be noted that the rheological behavior reflecting $M_{\mathrm{e}, \mathrm{melt}}\left(\right.$ or $M_{\mathrm{e}}$ ) appears in much shorter time region than the intermolecular associations described above. Dynamic viscoelasticity is examined for concentrated solutions by 
72 using an ionic liquid as a good solvent. Ionic liquids are known to dissolve several

73 polysaccharides which are insoluble to conventional organic solvents. For each of

74 galactomannans, $M_{\mathrm{e}}$ is determined as a function of the polymer concentration $(c)$, and then

$M_{\mathrm{e}, \text { melt }}$ is estimated by extrapolation of the $c$-dependence curve of $M_{\mathrm{e}}$.

\section{Experimental}

2.1. Materials

Galactomannan powders (g-gum, t-gum and lb-gum) were provided from

MRC-Polysaccharide Co., Japan. All samples were used without further purification. A solvent

1-butyl-3-methylimidazolium chloride (BmimCl; Aldrich, USA) was used as received.

According to the manufacturer's data sheet, the melting temperatures $\left(T_{\mathrm{m}}\right)$ of $\mathrm{BmimCl}$ was

reported to be $70{ }^{\circ} \mathrm{C}$. The galactomannan solutions in $\mathrm{BmimCl}$ were prepared as follows: The powders were added into liquid $\mathrm{BmimCl}$ in a dry glass vessel, and then the mixture was quickly 
90 were commonly assumed to be $10^{3} \mathrm{kgm}^{-3}$, since the values for the purely amorphous polymers

91 are not available (Horinaka, Yasuda, Takigawa, 2011a). The viscoelasticity measurements were

92 started just after finishing the sample preparation.

The dynamic viscoelasticity measurements were carried out with an ARES rheometer (now

TA Instruments, USA) under a nitrogen atmosphere with a cone-plate geometry. The diameter of curves of the storage modulus $\left(G^{\prime}\right)$ and the loss modulus $\left(G^{\prime \prime}\right)$ were measured in the range of $\omega$

\section{Results and Discussion}


the $\omega$ dependence curves at different temperatures were well superimposed to give the master

110 frequency)-temperature superposition principle holds for these systems. The

111 frequency-dependence of loss tangent $\left(\tan \delta=G^{\prime \prime} / G^{\prime}\right)$ is also shown for the region in which the

112 curves pass through a minimum. The zero-shear viscosity $\left(\eta_{0}\right)$ of the solvent, $\mathrm{BmimCl}$, at $T_{\mathrm{r}}$ of

$11380{ }^{\circ} \mathrm{C}$ was much smaller than that of the solutions examined here, and therefore the contribution

114 of $\eta_{0}$ of the solvent to $G$ ' was ignored. At low $\omega a_{T}$ the flow region can be seen clearly on the $G^{\prime}$

115 and $G$ " curves. In the middle $\omega a_{T}$ region in the figure the rubbery plateau exists on both $G$ '

116 curves. The rubbery plateau originates from the entanglement coupling between polymer chains,

117 indicating the existence of entanglements between g-gum chains. The tilted plateau suggests

118 that the molecular weight distribution of the g-gum is broad.

119 Figures 1 (b) and (c) show the master curves of $G^{\prime}$ and $G$ "' for the solutions of t-gum and lb-gum, respectively. Similar viscoelastic behavior to the g-gum solutions is observed for these galactomannans.

Figures 2 shows $\log a_{T}\left(T_{\mathrm{r}}=80{ }^{\circ} \mathrm{C}\right)$ plotted against $1 / T$ from 20 to $100{ }^{\circ} \mathrm{C}$ for the solutions of g-gum, t-gum and lb-gum. The shift factor $a_{T}$ at a given $T$ is almost the same regardless of $c$ and all data points fall on a single line. These are common to the three figures ((a) to (c)). The 
126 equation and that even below the melting point of $\mathrm{BmimCl}, a_{T}$ has the same $T$ dependence as

127 above the melting point. Similar behavior has been observed for other polysaccharides in

128 BmimCl (Horinaka, Yasuda, Takigawa, 2011a; Horinaka, Yasuda, Takigawa, 2012).

129 From the analogy with the rubber elasticity, $M_{\mathrm{e}}$ for a polymer at a concentration $c$ can be calculated by

$$
M_{\mathrm{e}}=\frac{10^{3} c R T}{G_{\mathrm{N}}^{0}}
$$

132 Here, $G_{N}^{0}$ is the plateau modulus in the rubbery region and $R$ is the gas constant. (Ferry, 1980;

133 Doi, \& Edwards, 1986; Onogi, Masuda, \& Kitagawa 1970) As stated previously, the actual G'

134 curves in this study were tilted, so that we defined here $G_{N}^{0}$ as the $G^{\prime}$ value at $\omega a_{\mathrm{T}}$ where the $\tan \delta$ versus $\omega$ curve stays at a minimum. This leads to the results that the $5.4 \times 10^{1}$ and $2.1 \times 10^{2}$ $\mathrm{kgm}^{-3}$ solutions of g-gum respectively have $G_{N}^{0}$ of $1.6 \times 10^{3}$ and $3.2 \times 10^{4} \mathrm{~Pa}$ (Figure 1(a)), finally giving $M_{\mathrm{e}}$ of $9.8 \times 10^{4}$ and $2.0 \times 10^{4}$, respectively. The values of $M_{\mathrm{e}}$ for the solutions of other galactomannans were obtained in a similar way. each galactomannan, a straight line with a slope of -1 is drawn with the best fit method. This is

141 based on the assumption that a relation for polymers $M_{\mathrm{e}} \propto c^{-1}$ is also applied to the 
144 line of slope -1 , indicating that the $c^{-1}$ dependence of $M_{\mathrm{e}}$ also holds well for the galactomannan

145 solutions examined in this study. Comparing the values of $M_{\mathrm{e}}$ at a given $c$, we have the order

146 g-gum $>$ t-gum $>$ lb-gum although the difference between t-gum and lb-gum is rather small. The

147 quantity, $M_{\mathrm{e}, \mathrm{melt}}$ for the galactomannans can be determined as a value of the intercept on the

148 right-hand ordinate in Figure 3 (or, more precisely, the value of $M_{\mathrm{e}}$ at $c=10^{3} \mathrm{kgm}^{-3}$ ), by

149 assuming the density of all galactomannans to be $1.0 \times 10^{3} \mathrm{kgm}^{-3}$. The obtained values of $M_{\mathrm{e}, \mathrm{melt}}$

150 are $4.6 \times 10^{3}, 3.2 \times 10^{3}$, and $2.7 \times 10^{3}$ for g-gum, t-gum and lb-gum, respectively; namely, $M_{\mathrm{e}, \mathrm{melt}}$

151 becomes smaller with increasing the $\mathrm{m} / \mathrm{g}$ ratio. Since $M_{\mathrm{e}, \mathrm{melt}}$ is a material constant, it is

152 interesting to calculate the number of monosaccharide units between entanglements in the

153 molten state $\left(N_{\text {unit }}\right)$ from $M_{\text {e,melt }}$ and $M_{\text {unit, }}$, with $M_{\text {unit }}$ being the molecular weight of a repeating

154 unit for the galactomannans. Here, $M_{\text {unit }}$ was calculated based on the assumption that the $\mathrm{m} / \mathrm{g}$

155 ratios are the typical values, i.e., 2 for g-gum, 3 for t-gum, and 4 for $1 \mathrm{lb}$-gum, and that a galactose

156 side group was included in a unit. We define $N_{\text {unit }}$ as the number of mannose units along the

main chain, not counting a galactose side group, i.e., $N_{\text {unit }}=$ (the number of mannose units in a

unit $) \times\left(M_{\mathrm{e}, \mathrm{melt}} / M_{\text {unit }}\right)$. Table 1 lists $N_{\text {unit }}$ for the galactomannans together with $M_{\mathrm{e} \text {,melt }}$ and $M_{\text {unit }}$.

The values of $N_{\text {unit }}$ lie in almost the same range (13 to 19). If we see them more precisely, 
162 our previous studies. We have 19 for cellulose, 15 for agarose and 14 for gellan, which are

163 almost the same and are typical for polysaccharides with the random-coil conformation in the

164 ionic liquid (Horinaka, Yasuda, \& Takigawa, 2011a). The values for the galactomannans are

165 really close to those of the other polysaccharides with the random coil conformation, suggesting

166 that the galactomannans in the ionic liquid here take the random coil conformation. This is, at

167 least for g-gum, consistent with the previous prediction made from the intrinsic viscosity measurement that a g-gum molecule behaves as a random coil in water (Robinson,

\section{Conclusions}

Dynamic viscoelasticity of concentrated solutions of g-gum, t-gum, and lb-gum in

$173 \mathrm{BmimCl}$ was examined to estimate $M_{\mathrm{e}, \text { melt }}$ of the galactomannans. The values of $M_{\mathrm{e}, \mathrm{melt}}$ are

$4.6 \times 10^{3}, 3.2 \times 10^{3}$, and $2.7 \times 10^{3}$ for g-gum, t-gum, and lb-gum, respectively; namely, $M_{\mathrm{e}, \text { melt }}$ for the galactomannans is dependent on the $\mathrm{m} / \mathrm{g}$ ratio. As a whole, however, $N_{\text {unit }}$ for the three galactomannans are rather close to each other being in the same range as for other polysaccharides such as cellulose and agarose. This suggests that the galactomannans take the 
182

183

184

185

186

187

188

189

190

191

193

194

195

196

197

198

199

\section{References}

Cerqueira, M. A., Bourbon, A. I., Pinheiro, A. C., Martins, J. T., Souza, B. W. S., Teixeira, J. A., \& Vicente, A. A. (2011). Galactomannans use in the development of edible films/coatings for food applications. Trends in Food Science \& Technology. 22, 662-671.

Doi, M., \& Edwards, S. F. (1986). The theory of polymer dynamics. Oxford: Clarendon.

Ferry, J. D. (1980). Viscoelastic properties of polymers. New York: John Wiley \& Sons.

Horinaka, J., Yasuda, R., \& Takigawa, T. (2009). Rheological Properties of Concentrated Solutions of Gellan in an Ionic Liquid. Carbohydr. Polym., 78, 576-580.

Horinaka, J., Yasuda, R., \& Takigawa, T. (2011)a. Entanglement properties of cellulose and amylose in an ionic liquid. J. Polym. Sci. B: Polym. Phys., 49, 961-965.

Horinaka, J., Yasuda, R., \& Takigawa, T. (2011)b. Entanglement network of agarose in various solvents. Polymer J., 43, 1000-1002.

Horinaka, J., Yasuda, R., \& Takigawa, T. (2012). Rheological properties of concentrated solutions of agarose in ionic liquid. J. Appl. Polym. Sci., 123, 3023-3027.

Masuda, T., Toda, N., Aoto, Y., \& Onogi, S. (1972). Viscoelastic properties of concentrated solutions of poly(methyl methacrylate) in diethyl phthalate. Polym. J., 3, 315-321.

McCleary, B. V., Amado, R., Waibel, R., \& Neukom, H. (1981). Effect of galactose content on the solution and interaction properties of guar and carob galactomannans. Carbohydr. Res., 
Morris, E. R., Cutler, A. N., Ross-Murphy, S. B., \& Rees, D. A. (1981). Concentration and shear rate dependence of viscosity in random coil polysaccharide solutions. Carbohydr. Polym., 1, $5-21$.

Nemoto, N., Ogawa, T., Odani, H., \& Kurata, M. (1972). Shear creep studies of

narrow-distribution poly(cis-isoprene). III. concentrated solutions. Macromolecules, 5, 641-644.

Onogi, S., Masuda, T., \& Kitagawa K.(1970). Rheological properties of anionic polystyrenes. I. dynamic viscoelasticity of narrow-distribution polystyrenes. Macromolecules, 3, 109-116.

Richardson, R. K., \& Ross-Murphy, S. B. (1987). Non-linear viscoelasticity of polysaccharide solutions. 1: guar galactomannan solutions. Int. J. Biol. Macromol., 9, 250-256.

Robinson, G., Ross-Murphy, S. B., \& Morris, E. R. (1982). Viscosity-molecular weight relationships, intrinsic chain flexibility, and dynamic solutions properties of guar galactomannan. Carbohydr. Res., 107, 17-32.

213 Sanderson, G. R. (1990). Imeson, A. (Ed.) Food gels. New York: Elsevier Applied Science.

214 Sittikijyothin, W., Torres, D., \& Goncalves, M. P. (2005). Modeling the rheological behavior of 215 galactomannan aqueous solutions. Carbohydr. Polym., 59, 339-350.

216 Urlacher, B., \& Dalbe, B. (1994). Imeson, A. (Ed.) Thickning and gelling agents for food. 217 London: Blackie Academic and Professional, 257-273. 
218 Wientjes, R. H. W., Duit, M. H. G., Jongschaap, R. J. J., \& Mellema, J. (2000). Linear rheology

219 of guar gum solutions. Macromolecules, 33, 9594-9605.

220 Wu, Y., Cui, W., Eskin, N. A. M., \& Goff, H. D. (2009). An investigation of four commercial

221 galactomannan on their emulsion and rheological properties. Food Res. Int., 42, 1141-1146.

222 Wu, Y., Li, W., Cui, W., Eskin, N. A. M., \& Goff, H. D. (2012). A molecular modeling approach to understand conformation-functionality relationships of galactomannans with different mannose/galactose ratios. Food Hydrocolloids, 26, 359-364. 


\section{Figure Captions}

Figure 1 Master curves of $\omega$ dependence of $G^{\prime}$ and $G^{\prime}$ for $5.4 \times 10^{1}$ and $2.1 \times 10^{2} \mathrm{kgm}^{\square 3}$ solutions of (a) g-gum, (b) t-gum, and (c) lb-gum. $T_{\mathrm{r}}=80^{\circ} \mathrm{C}$. The $\tan \delta$ curve is also included.

Figure 2 Shift factor for (a) g-gum, (b) t-gum, and (c) lb-gum solutions of $c$ from $5.4 \times 10^{1}$ to $2.1 \times 10^{2} \mathrm{kgm}^{-3}$ plotted against the reciprocal of $T$. In each figure, all data points fall on a single line

Figure 3 Double-logarithmic plot of $M_{\mathrm{e}}$ against $c$ for galactomannans in solution. Each line is the best fit with a slope of $\square 1 . M_{\mathrm{e}, \text { melt }}$ for galactomannans are determined as $M_{\mathrm{e}}$ at $c=$ $10^{3} \mathrm{kgm}^{-3}$. 


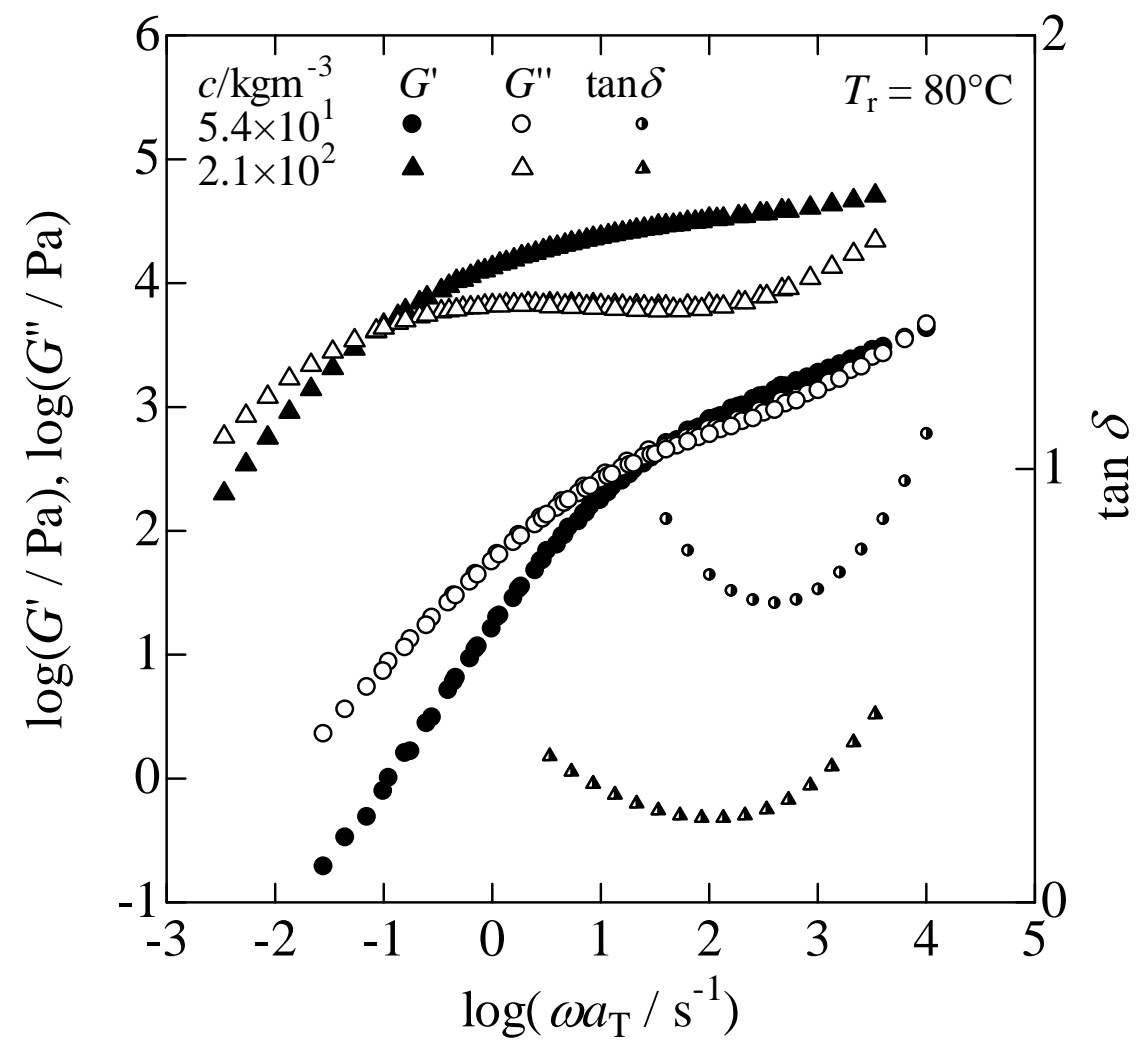

Fig. 1(a) 


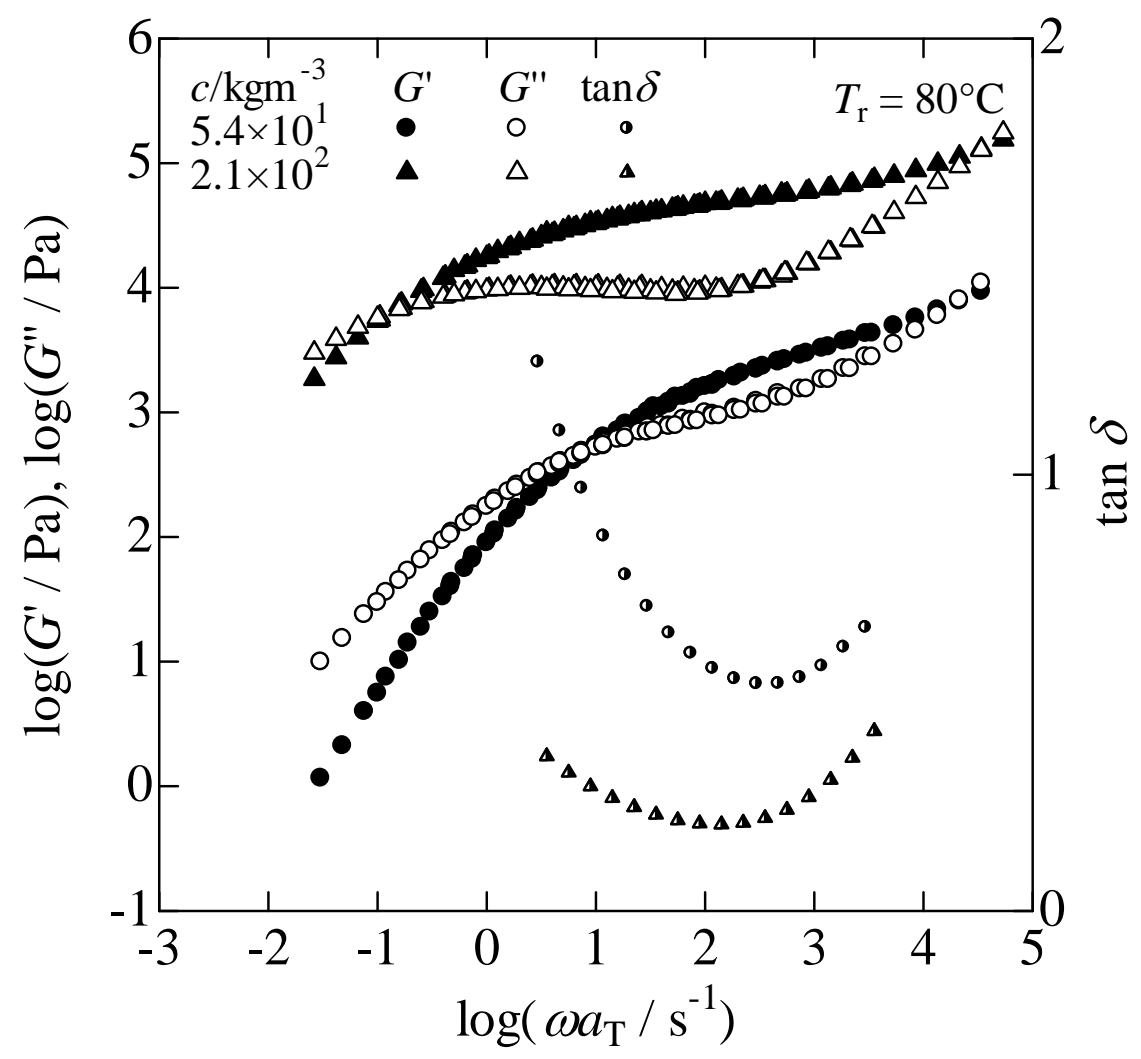

Fig. 1(b) 


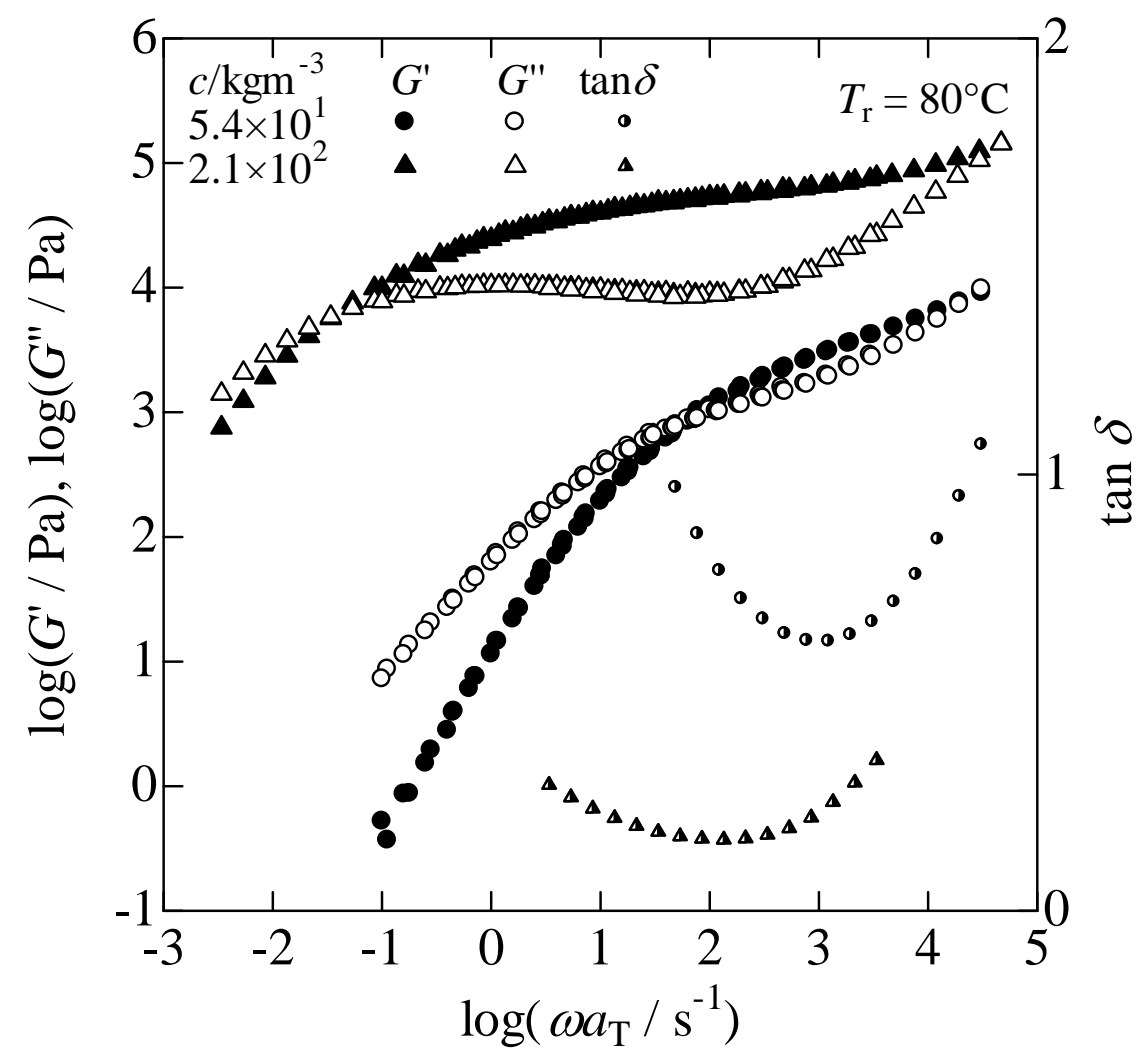

Fig. 1(c) 


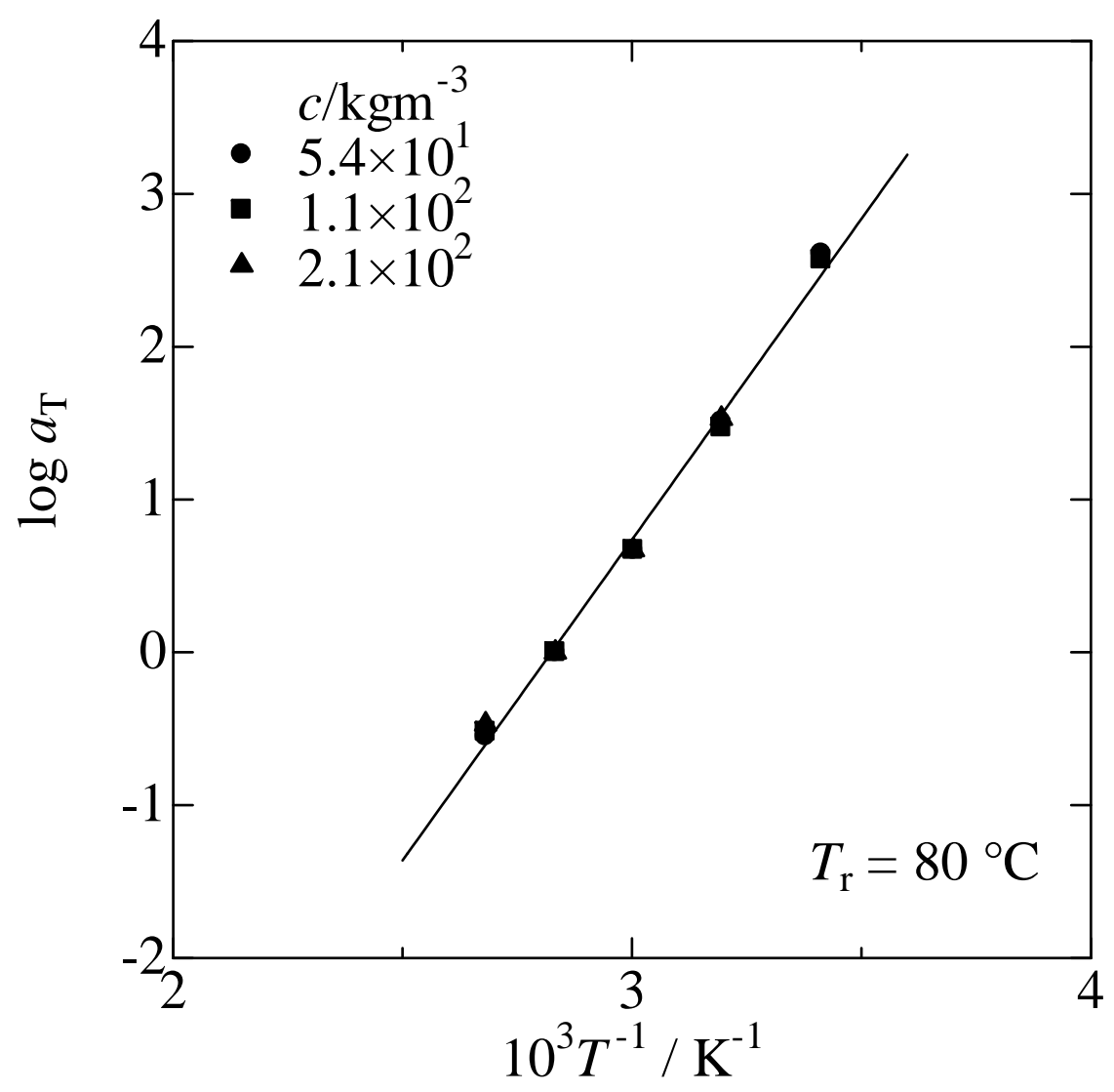

Fig. 2(a) 


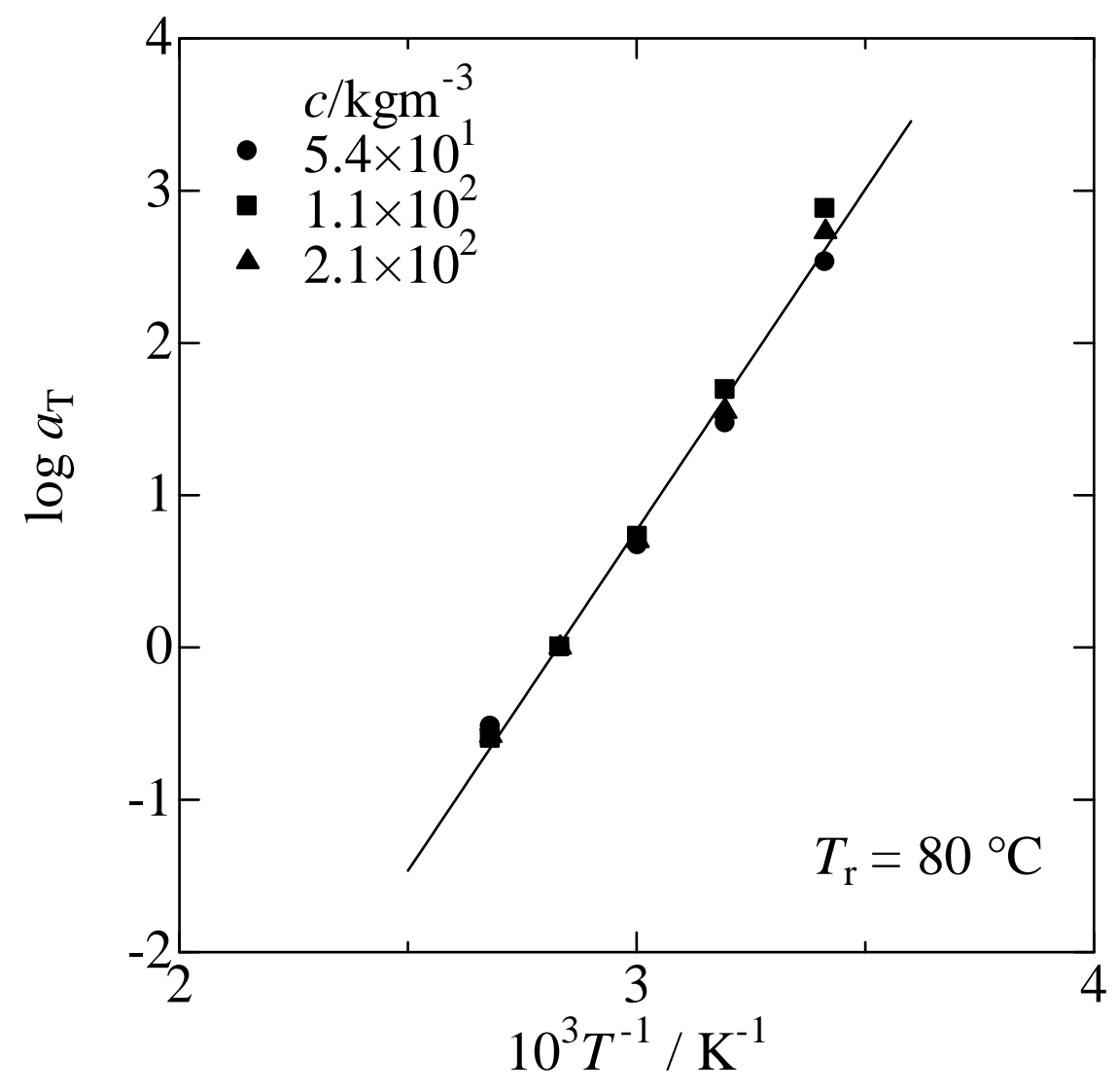

Fig. 2(b) 


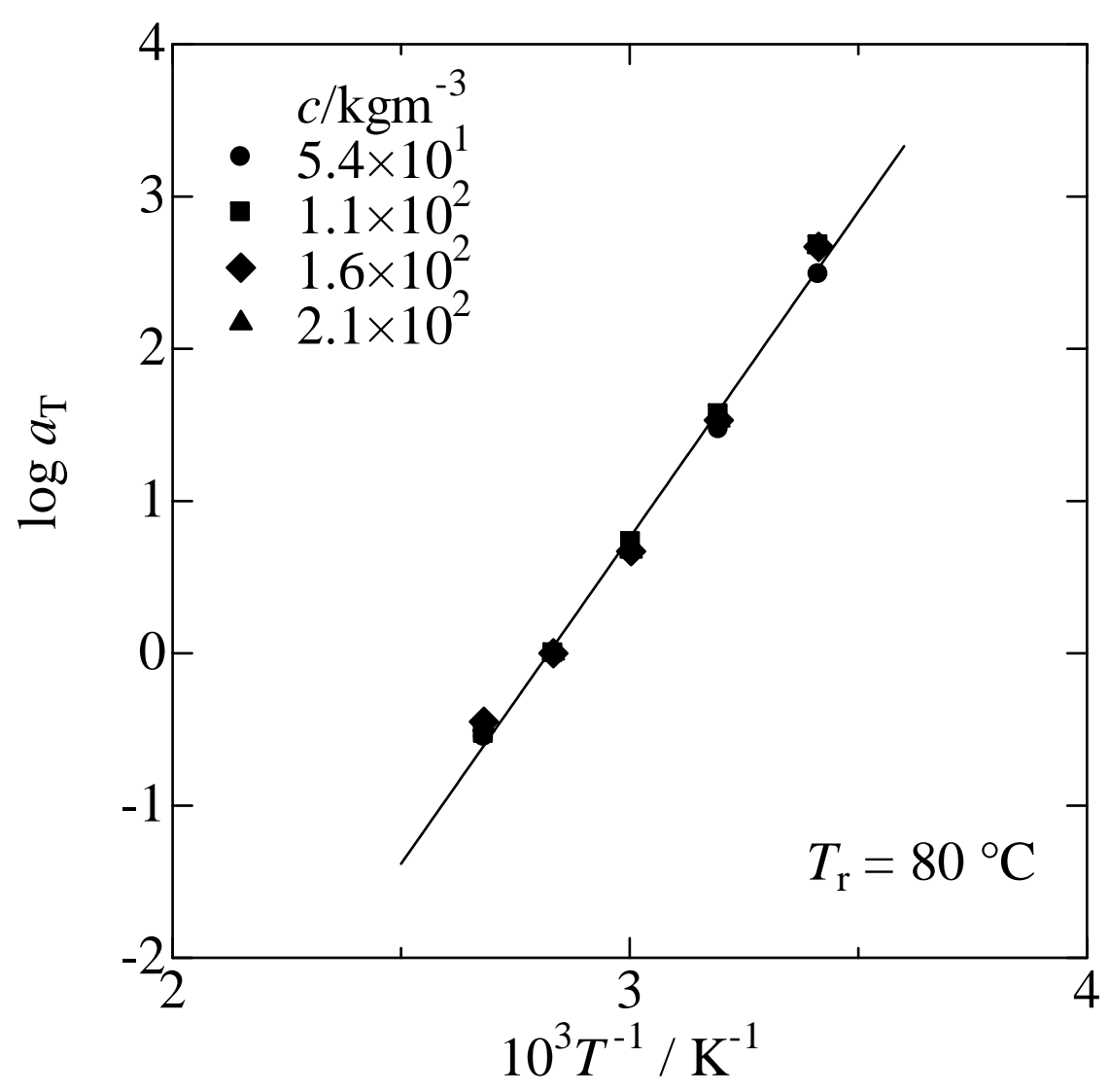

Fig. 2(c) 


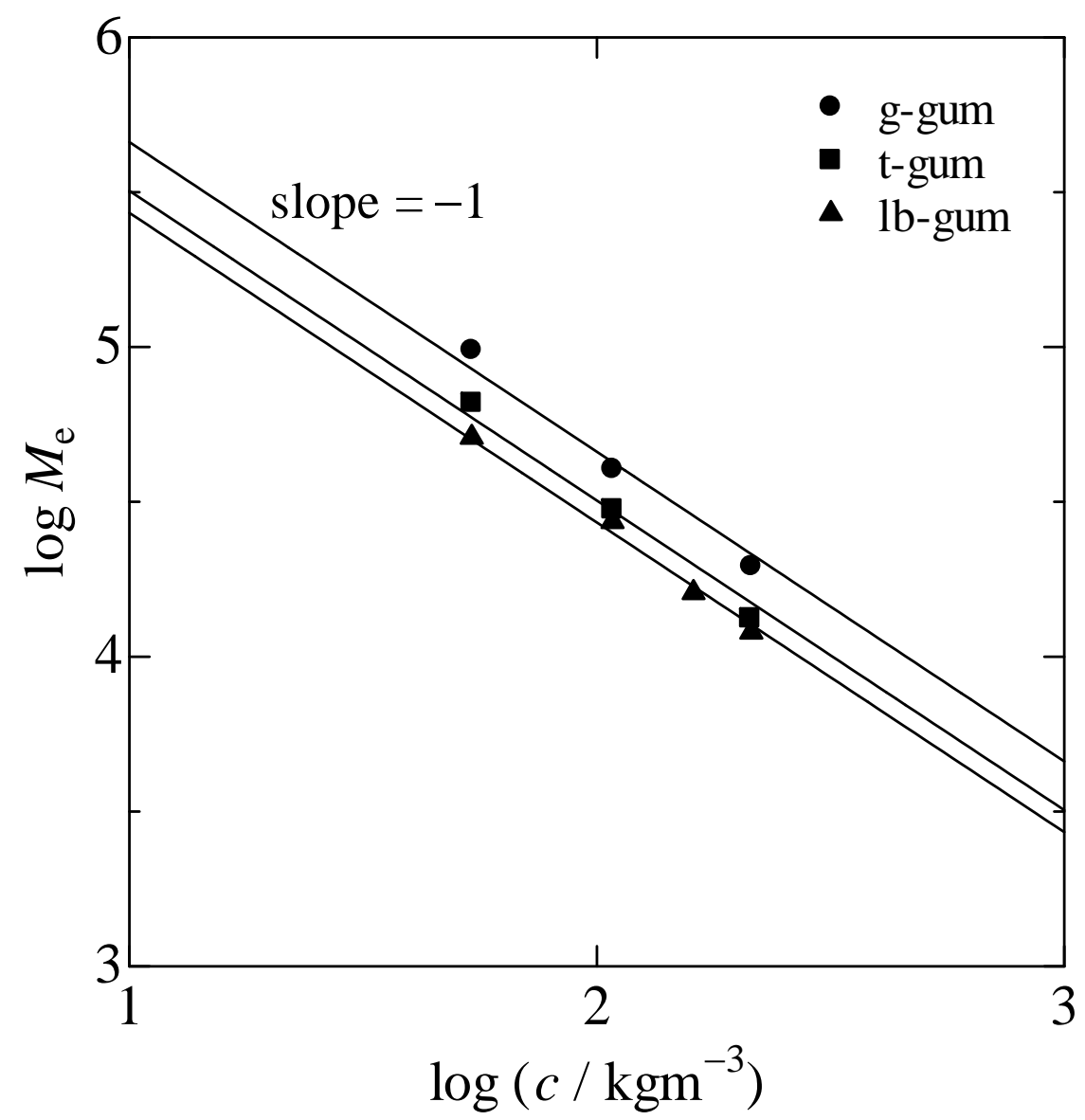

Fig. 3 
Table 1. Material constants for galactomannans

\begin{tabular}{llll}
\hline sample & $M_{\text {unit }}$ & $M_{\mathrm{e}, \text { melt }}$ & $N_{\text {unit }}{ }^{*}$ \\
\hline g-gum & 486 & $4.6 \times 10^{3}$ & 19 \\
t-gum & 648 & $3.2 \times 10^{3}$ & 15 \\
lb-gum & 810 & $2.7 \times 10^{3}$ & 13 \\
\hline
\end{tabular}

* excluding a galactose side group 